\title{
Atomic Spectroscopy . \\ Determination of Silver in Geological Samples Using Aerosol Dilution ICP-MS After Water-bath Extraction with Inverse Aqua Regia
}

\author{
Yan Wu, ${ }^{\text {a }}$ Dingming Huang, ${ }^{\text {a }}$ Tong Feng, ${ }^{\text {a }}$ Lanlan Jin,,${ }^{\mathrm{a}, *}$ Dan Xiong, $,{ }^{\mathrm{b}, *} \mathrm{JieYu},{ }^{\mathrm{a}} \mathrm{Qian} \mathrm{Xu} \mathrm{u}^{\mathrm{a}}$, \\ Ruimin Huang, ${ }^{\mathrm{c}}$ and Shenghong $\mathrm{Hu}^{\mathrm{a}}$ \\ a State Key Laboratory of Biogeology and Environmental Geology, School of Earth Sciences, China University of Geosciences, Wuhan 430074, P.R. China \\ ${ }^{\text {b }}$ Suizhou Center for Disease Control and Prevention, Suizhou 441300, P.R. China \\ c Institute of Agricultural Quality Standards and Testing Technology Research, Fujian Academy of Agricultural Sciences, Fujian Key Laboratory of Quality \\ and Safety of Agri-Products, Fuzhou 350003, P.R. China
}

Received: August 25, 2021; Revised: October 01, 2021; Accepted: October 01, 2021; Available online: October 22, 2021.

DOI: $10.46770 / A S .2021 .906$

\begin{abstract}
A valid method for trace silver (Ag) detection in geological samples was developed in this study using aerosol dilution inductively coupled plasma-mass spectrometry after extraction with inverse aqua regia. This was proposed primarily to reduce the interference from $\mathrm{Nb}$ and $\mathrm{Zr}$ during mass spectrometric measurements. Almost $93 \% \mathrm{of} \mathrm{Nb}$ and $\mathrm{Zr}$ was removed after the extraction. By mixing an appropriate amount of Ar with the sample aerosol using an aerosol dilution system prior to plasma, the residual $\mathrm{Nb}$ oxides and $\mathrm{Zr}$ oxides or hydroxides could be successfully removed. The relative yields of the interfering oxides and hydroxides were as low as $0.087 \%(\mathrm{NbO} / \mathrm{Nb})$ and $0.013 \%(\mathrm{ZrOH} / \mathrm{Zr})$, which were 3-5 times lower than those in the traditional mode without the addition of Ar. Moreover, the signal-to-noise ratio of Ag was five times higher than that in the traditional mode. The proposed method was applied to the determination of $\mathrm{Ag}$ in 68 standard reference materials (SRMs) of soil, sediment, and rock. The results for 47 of these geological SRMs were in good agreement with the reference values. The Ag levels in three SRMs (GSP-2 Granodiorite, STM-2, and SGR-1b) are being reported for the first time herein. For these SRMs, 10 separate aliquots of the sample were digested and analyzed over a period of three months, and analysis revealed that the determined values were reasonable. Thus, the proposed method shows significant potential for the accurate determination of trace $\mathrm{Ag}$ in various geological samples.

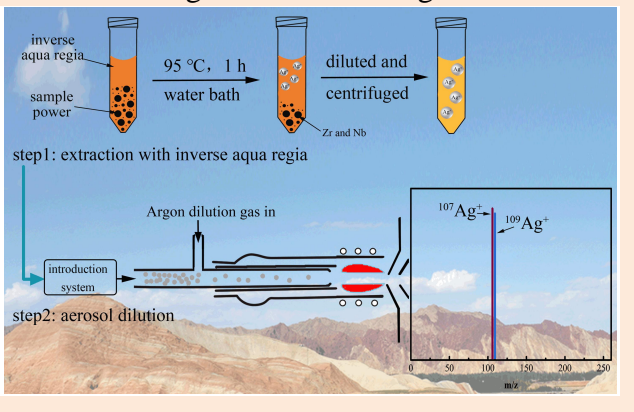

\section{INTRODUCTION}

$\mathrm{Ag}$ is an important indicator in geochemical research as it facilitates the exploration of geochemical anomalies of precious and non-ferrous metals and aids in understanding the enrichment and variation of elements and the origin of deposits, establishing geological prospecting criteria, and assessing mineral resources. ${ }^{1,2}$ Therefore, accurate determination of silver $(\mathrm{Ag})$ content in geochemical samples is important. However, $\mathrm{Ag}$ is usually present in low concentrations in geological samples except Ag deposits. The average abundance of Ag in the earth's crust is only $0.056 \mu \mathrm{g} \mathrm{g}^{-1}$, and hence, the accurate quantification of $\mathrm{Ag}$ is extremely difficult. ${ }^{2}$
Various atomic spectrometric techniques, including flame atomic absorption spectrometry, ${ }^{3,4}$ graphite furnace atomic absorption spectrometry, ${ }^{5-7}$ electrothermal atomic absorption spectrometry, ${ }^{8,9}$ emission spectrometry, ${ }^{10-12}$ inductively coupled plasma optical emission spectrometry, ${ }^{13-16}$ microwave plasma atomic emission spectrometry, ${ }^{17}$ and inductively coupled plasma-mass spectrometry (ICP-MS), ${ }^{18-20}$ have been used for Ag detection in different samples.

ICP-MS is highly sensitive and selective for the determination of trace elements, ${ }^{21-23}$ hence, it is also preferred for the determination of trace $\mathrm{Ag}$. The determination of trace $\mathrm{Ag}$ by ICP-MS suffers from the interference of polyatomic ions of $\mathrm{Nb}$, 


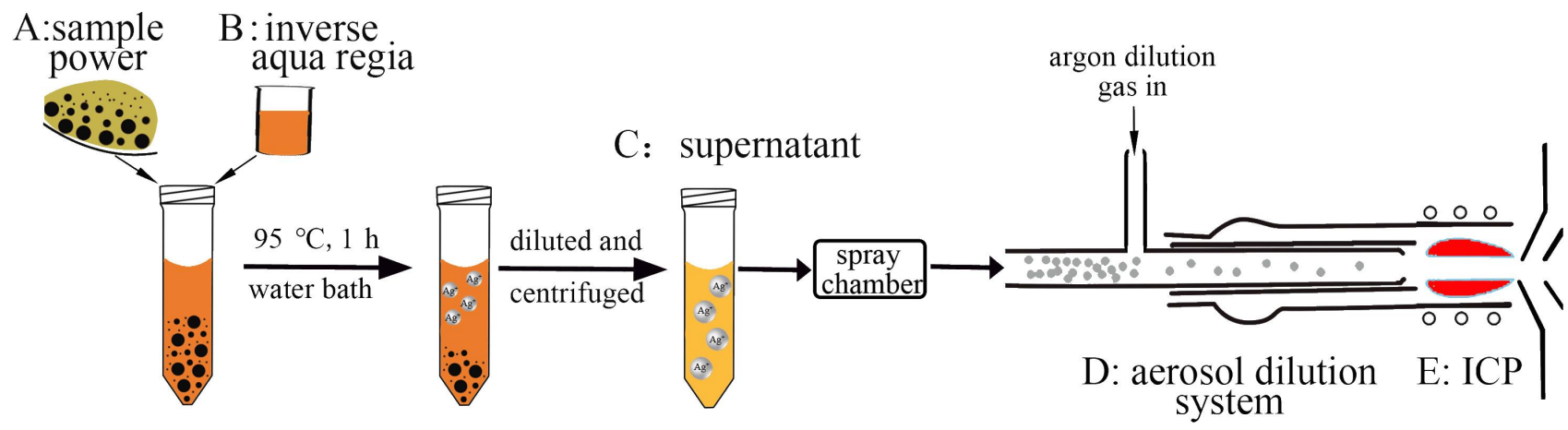

Fig. 1 Schematic diagram of aerosol dilution ICP-MS after extraction with inverse aqua regia: (A) homogenized sample powder (200 mesh); (B) inverse aqua regia solution $\left(\mathrm{HNO}_{3}: \mathrm{HCl}=3: 1\right)$; (C) supernatant; (D) aerosol dilution system; (E) ICP.

$\mathrm{Zr}$, Mo, and Y; for example, ${ }^{107} \mathrm{Ag}$ interferes with ${ }^{90} \mathrm{Zr}^{16} \mathrm{OH}^{+}$, ${ }^{91} \mathrm{Zr}^{16} \mathrm{O}^{+}$, and ${ }^{89} \mathrm{Y}^{18} \mathrm{O}^{+}$, while ${ }^{109} \mathrm{Ag}$ interferes with ${ }^{93} \mathrm{Nb}^{16} \mathrm{O}^{+}$, ${ }^{92} \mathrm{Zr}^{16} \mathrm{OH}^{+}$, and ${ }^{92} \mathrm{Mo}^{16} \mathrm{OH}^{+}$. In particular, the abundances of $\mathrm{Nb}$, $\mathrm{Zr}$, Mo, and $\mathrm{Y}$ in the continental crust are 150-fold, 2300-fold, 14-fold, and 340-fold higher, respectively, than that of $\mathrm{Ag}(\mathrm{Nb}=$ $12 \mu \mathrm{g} \mathrm{g}^{-1}, \mathrm{Zr}=193 \mu \mathrm{g} \mathrm{g}^{-1}, \mathrm{Mo}=1.1 \mu \mathrm{g} \mathrm{g}^{-1}$, and $\left.\mathrm{Y}=21 \mu \mathrm{g} \mathrm{g}^{-1}\right)$, leading to erroneous results for trace $\mathrm{Ag}$ detection in geological samples. ${ }^{1}$

To eliminate the spectral interference in the determination of $\mathrm{Ag}$ by ICP-MS, a series of methods have been employed, including the incorporation of correction formulae; ${ }^{24}$ preconcentration and separation with $\mathrm{P} 507$ resin, ${ }^{25}$ thiourea resin, ${ }^{26,27}$ and chitosan-based chelating resin, ${ }^{28}$ use of extraction technologies for sample digestion; ${ }^{29-32}$ development of membrane desolvation and sample introduction techniques; ${ }^{33}$ and conducting ion-molecule reactions in a dynamic reaction cell (DRC). ${ }^{34,35}$ These techniques can measure the $\mathrm{Ag}$ content accurately to some extent; however, these separation methods either cannot eliminate the interference completely, or are time-consuming, or require special instrumental setups or expensive equipment. An online dilution technology, in which the sample aerosol was diluted online with Ar before it entered the plasma, has been used to suppress oxide formation. When a dilution gas was added, the aerosol entering the plasma contained much less water and acid, resulting in more robust plasma and ten times lower oxide formation, which will not significantly compromise the detection limits. This technique has been applied to the analysis of trace elements in complex matrices, without the involvement of complex preprocessing.

The main purpose of this work was to develop a valid method for the determination of trace Ag in geological samples. for the determination of trace $\mathrm{Ag}$ in geological samples. Water-bath extraction with inverse aqua regia and online aerosol dilution ICP-MS were combined to eliminate complex interferences from the polyatomic $\mathrm{Zr}$ and $\mathrm{Nb}$ species. After optimizing the parameters of this method, a series of 68 geological standard reference materials (SRMs) of different types were examined to evaluate the performance of this method in detail.
Table 1. Typical Parameters of the ICP-MS System

\begin{tabular}{lc}
\hline Parameters & Value \\
\hline RF power, W & 1450 \\
Nebulizer gas flow, Lmin $^{-1}$ & 0.25 \\
Dilution gas flow, Lmin $^{-1}$ & 0.85 \\
Sampling depth, Lmin $^{-1}$ & 8.0 \\
Sweeps per reading, $\mathbf{~ m s ~}$ & 25 \\
Reading per replicate & 3 \\
${ }^{156} \mathbf{C e O} /{ }^{140}$ Ce ratio, \% & Aerosol dilution model $<0.3$ \\
& Standard model $<3$ \\
Isotopic monitored & ${ }^{109} \mathrm{Ag}$ \\
\hline
\end{tabular}

\section{Experimental}

Analytical Instrumentation. An Agilent 7700x ICP-MS (Agilent Technologies, USA) instrument equipped with an aerosol dilution system (Fig. 1), a MicroMist nebulizer, and a Peltier-cooled $\left(2^{\circ} \mathrm{C}\right)$ quartz Scott-type double-pass spray chamber was used for this work. The operating parameters for ICP-MS were optimized with a tuning solution $\left(1.0 \mathrm{ng} \mathrm{mL}^{-1}\right.$ of $\mathrm{Ce}, \mathrm{Co}, \mathrm{Li}, \mathrm{Mg}, \mathrm{Tl}$, and $\mathrm{Y}$ ) prior to determination to obtain the maximum signal intensities and the minimum oxide formation rate $\left(\mathrm{CeO}^{+} / \mathrm{Ce}^{+}\right)$and doubly charged ratio $\left(\mathrm{Ce}^{2+} / \mathrm{Ce}^{+}\right)$. The typical instrumental operating conditions and measurement parameters are listed in Table 1.

Reagents. All blanks, standards, and samples were prepared using 18.2 $\mathrm{M} \Omega \mathrm{cm}$-ultrapure water produced by a water purification system (90005-02, LabconcoWaterPro PS, USA). Ultra-pure hydrochloric acid $(\mathrm{HCl})$ and nitric acid $\left(\mathrm{HNO}_{3}\right)$ were prepared from guaranteed grade reagents (Alfa Aesar Ltd., Tianjin) using a two-bottle Teflon sub-boiling distillation system (Savillex Corporation, USA). Single-element stock solutions (Cd, $\mathrm{Ag}, \mathrm{Zr}, \mathrm{Nb}$, and $\mathrm{Rh}$ ) were purchased from the National Center for Analysis and Testing of Steel Materials (Beijing, P.R. China). The accuracy of the method was assessed using 11 geological SRMs from the United States Geological Survey and 58 SRMs from the Institute of Geophysical and Geochemical Prospecting (P.R. China). 

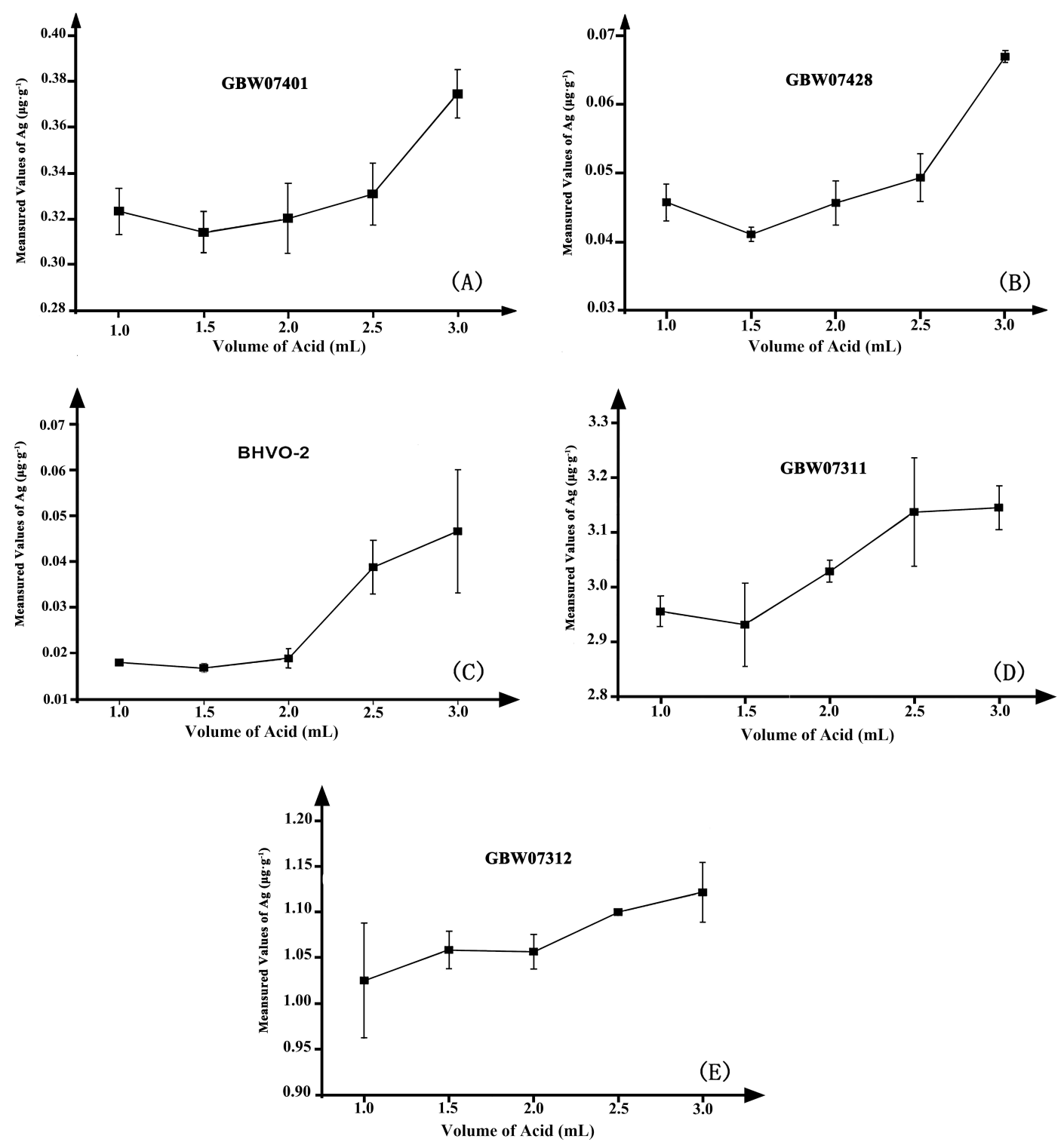

Fig. 2 Effect of inverse aqua regia volume on Ag levels.

Table 2. Ag Levels in 5 Geological SRMs at Different Bath Temperatures $\left(\mu \mathrm{g} \mathrm{g}^{-1}\right)$

\begin{tabular}{lcccc}
\hline \multirow{2}{*}{ Reference Materials } & \multicolumn{3}{c}{ Measured Values } & Reference \\
& $\mathbf{6 5}^{\circ} \mathbf{C}$ & $\mathbf{6 5}^{\circ} \mathbf{C}$ & $\mathbf{9 5}^{\circ} \mathbf{C}$ & Values \\
\hline GBW07304 & 0.069 & 0.078 & 0.076 & 0.084 \\
GBW07312 & 1.05 & 1.12 & 1.11 & 1.15 \\
GBW07447 & 0.067 & 0.063 & 0.066 & 0.066 \\
GBW07457 & 0.1 & 0.11 & 0.11 & 0.13 \\
GBW07121 & 0.022 & 0.024 & 0.024 & 0.03 \\
\hline
\end{tabular}

Sample Pretreatment. A homogenized sample powder (200 mesh, $0.2000 \mathrm{~g}$ ) was weighed into a $10 \mathrm{~mL}$ polyethylene centrifuge tube, and $3.0 \mathrm{~mL}$ of freshly prepared inverse aqua regia solution $\left(\mathrm{HNO}_{3}: \mathrm{HCl}=3: 1\right)$ was added. The centrifuge tube was then placed in a water bath at $95{ }^{\circ} \mathrm{C}$ for $1 \mathrm{~h}$. After cooling to about $25{ }^{\circ} \mathrm{C}$, the sample solution was diluted to $10 \mathrm{~mL}$ with high-purity water and centrifuged to remove the undissolved solid particles. Two milliliters of the supernatant were transferred to a new polyethylene tube and diluted with high-purity water to $6 \mathrm{~mL}$ (Fig. 1). For comparison, two conventional digestion methods, namely, closed pressurized digestion with a mixture of $\mathrm{HF}$ and $\mathrm{HNO}_{3}$ and electric heating plate digestion with aqua regia, were also used.

\section{RESULTS AND DISCUSSION}

Optimization of digestion conditions. During sample digestion, the amount of inverse aqua regia directly affects the recovery of the target elements and interfering elements. Five reference materials (GBW07401, GBW07428, GBW07311, GBW07312, and BHVO-2) were used to optimize the dosage of inverse aqua regia. Fig. 2 shows that the recovery of $\mathrm{Ag}$ increased with the volume of inverse aqua regia. Five milliliters of inverse aqua 
Table 3. Signal Intensity from $\mathrm{Ag}, \mathrm{Nb}, \mathrm{Zr}$ at $\mathrm{m} / \mathrm{z}=109$

\begin{tabular}{lcccc}
\hline & \multicolumn{4}{c}{ Signal Intensity / cps at $\mathbf{~ m / z = 1 0 9}$} \\
& $\begin{array}{c}\mathbf{A g}(\mathbf{1} \mathbf{~ n g} \\
\mathbf{m L}\end{array}$ & $\begin{array}{c}\mathbf{~ N b} \\
(\mathbf{2 0 0} \mathbf{~ n g} \\
\left.\mathbf{m L}^{-1}\right)\end{array}$ & $\begin{array}{c}\mathbf{Z r} \\
(\mathbf{2 0 0 0} \mathbf{~ n g} \\
\left.\mathbf{m L}^{-\mathbf{1}}\right)\end{array}$ & $\mathbf{S B R}$ \\
\hline $\begin{array}{l}\text { Standard Model } \\
\begin{array}{l}\text { Aerosol Dilution } \\
\text { Model }\end{array}\end{array}$ & 11224.6 & 17330.1 & 3866.1 & 0.53 \\
\hline
\end{tabular}

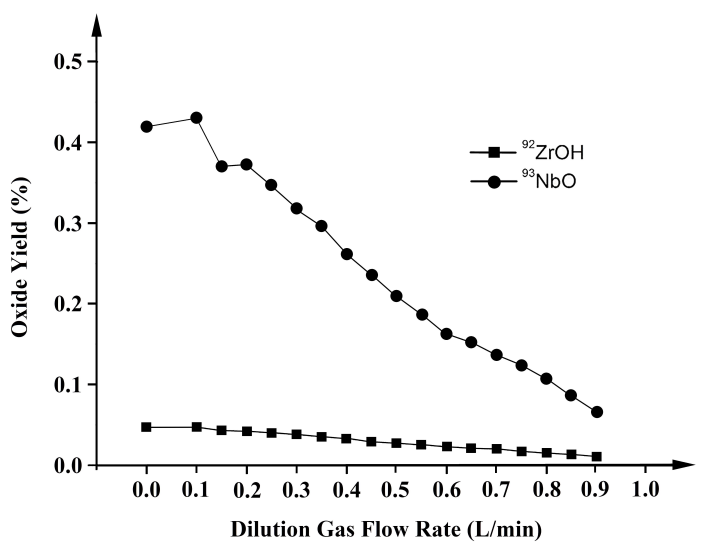

Fig. 3 Effect of the flow rate of dilution gas on oxide formation ratios $\left(\mathrm{ZrOH}^{+} / \mathrm{Zr}^{+}, \mathrm{NbO}^{+} / \mathrm{Nb}^{+}\right)$.

regia were used; the $\mathrm{Ag}$ content determined was consistent with the recommended value, while the recovery of $\mathrm{Nb}$ was lower than $7 \%$. Thus, $3 \mathrm{~mL}$ of inverse aqua regia was sufficient to dissolve Ag effectively from the sample; the interfering elements were not extracted, and the separation from the interfering elements was ascertained.

The effect of water bath temperature on the recovery of $\mathrm{Ag}$ was also investigated using five reference materials (GBW07447, GBW07457, GBW07304, GBW07312, and GBW07121). Digestion experiments were carried out at three temperatures $\left(25^{\circ} \mathrm{C}, 65^{\circ} \mathrm{C}\right.$, and $95^{\circ} \mathrm{C}$ ), and the errors between the measured values and the recommended values of $\mathrm{Ag}$ in these five reference materials were compared. Although the measured values of $\mathrm{Ag}$ in these five reference materials were within the acceptable error range atthe three water bath temperatures, the measured values were closer to the recommended values at higher temperatures $\left(65{ }^{\circ} \mathrm{C}\right.$ and $95{ }^{\circ} \mathrm{C}$ ) (Table 2). Therefore, the accuracy of $\mathrm{Ag}$ detection can be improved by increasing the water bath temperature, although there is no obvious relationship between these two factors. To ensure reliability of the analysis results, $\mathrm{Ag}$ was extracted from the samples at a water bath temperature of $95{ }^{\circ} \mathrm{C}$ for $1 \mathrm{~h}$.

Elimination of interference from polyatomic ions. Interferences in the determination of $\mathrm{Ag}$ in geological samples using ICP-MS are mainly from the $\mathrm{Zr}$-containing $\left({ }^{90} \mathrm{ZrOH},{ }^{91} \mathrm{ZrO}\right.$, $\left.{ }^{92} \mathrm{ZrOH}\right)$ and $\mathrm{Nb}$-containing $\left({ }^{93} \mathrm{NbO}\right)$ polyatomic ions. The aerosol dilution technique, in which an aerosol sample is diluted online with Ar prior to plasma, can minimize the interference from complex matrices (such as high-salt samples) on target elements and also the interference caused by liquid dilution by reducing the sample aerosol density in real time. More importantly, this online aerosol dilution technique can reduce the amount of water and acid entering the ICP. This not only maintains the high temperature of the ICP but also significantly minimizes the formation of interference ions such as oxides and other polyatomic ions. In this study, the aerosol dilution technique was used to reduce the interference of ${ }^{92} \mathrm{ZrOH}$ and ${ }^{93} \mathrm{NbO}$. Fig. 3 shows the relationship between $\mathrm{ZrOH}^{+} / \mathrm{Zr}^{+}$, $\mathrm{NbO}^{+} / \mathrm{Nb}^{+}$, and the flow rate of the dilution gas. The $\mathrm{ZrOH}^{+} / \mathrm{Zr}^{+}$ and $\mathrm{NbO}^{+} / \mathrm{Nb}^{+}$ratios decreased with increasing flow rate of the dilution gas. When this flow rate was $0.85 \mathrm{~L} / \mathrm{min}$, the two ratios decreased by 3-5 times compared with those in the traditional ICP-MS mode $\left(\mathrm{ZrOH}^{+} / \mathrm{Zr}^{+}=0.013 \%, \mathrm{NbO}^{+} / \mathrm{Nb}^{+}=0.087 \%\right)$.

Table 3 shows a comparison of the signal intensity and signal background ratio (SBR) of the traditional and aerosol dilution modes in ICP-MS, based on the simulated abundances of the

Table 4. Ag Levels in 5 Geological SRMs Determined Using this Method $\left(n=10, \mu \mathrm{g} \mathrm{g}^{-1}\right)$

\begin{tabular}{|c|c|c|c|c|c|}
\hline SRMs & GBW07402 & GBW07456 & GBW07359 & GBW07360 & GBW07105 \\
\hline \multirow{10}{*}{ Measured Values } & 0.066 & 0.138 & 0.048 & 0.781 & 0.031 \\
\hline & 0.057 & 0.179 & 0.047 & 0.752 & 0.027 \\
\hline & 0.063 & 0.156 & 0.048 & 0.735 & 0.029 \\
\hline & 0.056 & 0.154 & 0.043 & 0.834 & 0.034 \\
\hline & 0.051 & 0.154 & 0.054 & 0.815 & 0.024 \\
\hline & 0.052 & 0.168 & 0.048 & 0.682 & 0.033 \\
\hline & 0.051 & 0.171 & 0.050 & 0.770 & 0.030 \\
\hline & 0.055 & 0.147 & 0.043 & 0.761 & 0.033 \\
\hline & 0.058 & 0.150 & 0.048 & 0.809 & 0.030 \\
\hline & 0.052 & 0.160 & 0.053 & 0.738 & 0.044 \\
\hline Average Values & $0.056 \pm 0.005$ & $\begin{array}{c}0.16 \pm \\
0.01\end{array}$ & $\begin{array}{c}0.048 \pm \\
0.003\end{array}$ & $\begin{array}{c}0.77 \pm \\
0.04\end{array}$ & $\begin{array}{c}0.032 \pm \\
0.005\end{array}$ \\
\hline RSD, \% & 8.9 & 7.5 & 6.3 & 5.6 & 15.6 \\
\hline Reference Values & $0.054 \pm 0.007$ & $\begin{array}{c}0.14 \pm \\
0.01\end{array}$ & $\begin{array}{c}0.050 \pm \\
0.007\end{array}$ & $\begin{array}{c}0.74 \pm \\
0.14\end{array}$ & $\begin{array}{c}0.040 \pm \\
0.008\end{array}$ \\
\hline
\end{tabular}




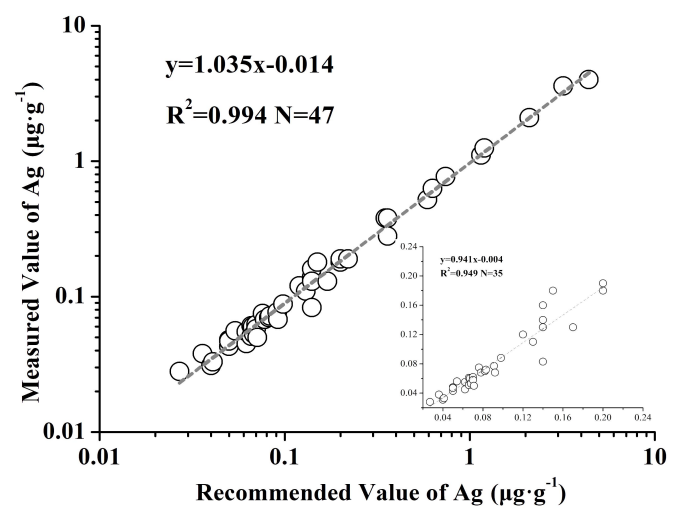

Fig. $4 \mathrm{Ag}$ values determined for 47 geological SRMs using the proposed method as a function of their certified values. The inset shows the values for the geological SRMs containing ultra-trace levels of $\mathrm{Ag}\left(<0.2 \mu \mathrm{gg}^{-1}\right)$. interfering elements ( $\mathrm{Zr}: 2000 \mathrm{ng} \mathrm{mL}^{-1}, \mathrm{Nb}: 200 \mathrm{ng} \mathrm{mL}^{-1}$ ) and $\mathrm{Ag}$ ( $1 \mathrm{ng} \mathrm{mL} \mathrm{m}^{-1}$ ) in continental crust. In the traditional mode, the signal response intensities of $\mathrm{Ag}, \mathrm{Nb}$, and $\mathrm{Zr}$ at m/z 109 were 11224.6, 17330.1, and $3866.1 \mathrm{cps}$, respectively, and the SBR was 0.53 . In the aerosol dilution mode, the corresponding signal response intensities were 2275.8, 738.7, and 247.2, respectively, while the SBR was 2.31. Although the signal intensity of Ag in the aerosol dilution mode was reduced by five times, the SBR increased by five times, which was more conducive for the accurate detection of $\mathrm{Ag}$.

Analysis procedure. The standard solution of $\mathrm{Ag}$ was diluted with $2 \%$ nitric acid to obtain a series of standard solutions with concentrations of $0,0.1,1,10$, and $100 \mathrm{ng} \mathrm{mL}^{-1}$. The working curve of $\mathrm{Ag}$ was obtained under the optimal working conditions. The detection limit of this method was $1.1 \mathrm{ng} \mathrm{g}^{-1}$ (considering a 300-fold dilution factor), which was 10 times the standard

Table 5. Ag Levels in 69 Geological SRMs Determined Using this Method $\left(\mu \mathrm{g} \mathrm{g}^{-1}\right)$

\begin{tabular}{|c|c|c|c|c|}
\hline & Sample Name & Character & Measured Values & Reference Values \\
\hline \multirow{30}{*}{ Soils } & GBW07401 & Dark brown soil & $0.38 \pm 0.028$ & $0.35 \pm 0.05$ \\
\hline & GBW07402 & Chestnut soil & $0.056 \pm 0.005$ & $0.054 \pm 0.007$ \\
\hline & GBW07403 & Yellow brown soil & $0.077 \pm 0.009$ & $0.091 \pm 0.007$ \\
\hline & GBW07404 & Weathered limestone soil & $0.045 \pm 0.005$ & $0.07 \pm 0.011$ \\
\hline & GBW07405 & Yellow red soil & $4.0 \pm 0.56$ & $4.4 \pm 0.4$ \\
\hline & GBW07406 & Yellow red soil & $0.18 \pm 0.015$ & $0.2 \pm 0.02$ \\
\hline & GBW07423 & Tillage soil & $0.075 \pm 0.006$ & $0.076 \pm 0.013$ \\
\hline & GBW07424 & Tillage soil & $0.072 \pm 0.008$ & $0.083 \pm 0.01$ \\
\hline & GBW07425 & Tillage soil & $0.088 \pm 0.006$ & $0.098 \pm 0.007$ \\
\hline & GBW07426 & Tillage soil & $0.068 \pm 0.008$ & $0.078 \pm 0.007$ \\
\hline & GBW07427 & Tillage soil & $0.060 \pm 0.004$ & $0.067 \pm 0.006$ \\
\hline & GBW07428 & Tillage soil & $0.051 \pm 0.004$ & $0.084 \pm 0.007$ \\
\hline & GBW07429 & Tillage soil & $0.18 \pm 0.015$ & $0.15 \pm 0.02$ \\
\hline & GBW07430 & Tillage soil & $0.14 \pm 0.002$ & $0.14 \pm 0.02$ \\
\hline & GBW07446 & Sandy soil & $0.028 \pm 0.003$ & $0.050 \pm 0.006$ \\
\hline & GBW07447 & Saline-alkali soil & $0.051 \pm 0.006$ & $0.066 \pm 0.005$ \\
\hline & GBW07448 & Brown desert soil & $0.043 \pm 0.004$ & $0.050 \pm 0.005$ \\
\hline & GBW07449 & Saline-alkali soil & $0.053 \pm 0.007$ & $0.068 \pm 0.007$ \\
\hline & GBW07450 & Sierozem soil & $0.036 \pm 0.004$ & $0.073 \pm 0.003$ \\
\hline & GBW07451 & Beach sediments & $0.044 \pm 0.004$ & $0.074 \pm 0.006$ \\
\hline & GBW07453 & Beach sediments & $0.052 \pm 0.004$ & $0.092 \pm 0.013$ \\
\hline & GBW07454 & Loess & $0.062 \pm 0.007$ & $0.070 \pm 0.008$ \\
\hline & GBW07455 & Sediment of Huaihe River & $0.058 \pm 0.004$ & $0.070 \pm 0.004$ \\
\hline & GBW07456 & Yangtze River Sediments & $0.16 \pm 0.01$ & $0.14 \pm 0.01$ \\
\hline & GBW07457 & Sediment of Xiangjiang River & $0.11 \pm 0.01$ & $0.13 \pm 0.01$ \\
\hline & GBW07302 & Stream sediment & $0.061 \pm 0.007$ & $0.066 \pm 0.010$ \\
\hline & GBW07303 & Stream sediment & $0.52 \pm 0.04$ & $0.59 \pm 0.05$ \\
\hline & GBW07305 & Stream sediment & $0.28 \pm 0.02$ & $0.36 \pm 0.03$ \\
\hline & GBW07306 & Stream sediment & $0.38 \pm 0.03$ & $0.36 \pm 0.03$ \\
\hline & GBW07309 & Stream sediment & $0.061 \pm 0.009$ & $0.089 \pm 0.010$ \\
\hline \multirow{3}{*}{ Stream sediments } & GBW07310 & Stream sediment & $0.055 \pm 0.007$ & $0.27 \pm 0.02$ \\
\hline & GBW07311 & Stream sediment & $3.6 \pm 0.15$ & $3.2 \pm 0.4$ \\
\hline & GBW07301a & Stream sediment & $0.038 \pm 0.007$ & $0.036 \pm 0.010$ \\
\hline
\end{tabular}




\begin{tabular}{|c|c|c|c|c|}
\hline & GBW07303a & Stream sediment & $0.19 \pm 0.01$ & $0.20 \pm 0.02$ \\
\hline & GBW07304a & Stream sediment & $0.19 \pm 0.008$ & $0.22 \pm 0.03$ \\
\hline & GBW07305a & Stream sediment & $0.63 \pm 0.06$ & $0.63 \pm 0.06$ \\
\hline & GBW07307a & Stream sediment & $1.25 \pm 0.09$ & $1.20 \pm 0.08$ \\
\hline & GBW07308a & Stream sediment & $0.12 \pm 0.01$ & $0.12 \pm 0.02$ \\
\hline & GBW07312 & Stream sediment & $1.11 \pm 0.09$ & $1.15 \pm 0.11$ \\
\hline & GBW07317 & Stream sediment & $0.013 \pm 0.003$ & $0.027 \pm 0.005$ \\
\hline & GBW07358 & Stream sediment & $0.13 \pm 0.009$ & $0.14 \pm 0.01$ \\
\hline & GBW07359 & Stream sediment & $0.048 \pm 0.003$ & $0.050 \pm 0.007$ \\
\hline & GBW07360 & Stream sediment & $0.77 \pm 0.04$ & $0.74 \pm 0.14$ \\
\hline & GBW07361 & Stream sediment & $0.015 \pm 0.003$ & $0.044 \pm 0.014$ \\
\hline & GBW07362 & Stream sediment & $0.068 \pm 0.005$ & $0.092 \pm 0.005$ \\
\hline & GBW07363 & Stream sediment & $0.070 \pm 0.003$ & $0.082 \pm 0.008$ \\
\hline & GBW07364 & Stream sediment & $0.083 \pm 0.006$ & $0.14 \pm 0.01$ \\
\hline & GBW07365 & Stream sediment & $0.044 \pm 0.01$ & $0.068 \pm 0.010$ \\
\hline & GBW07366 & Stream sediment & $2.1 \pm 0.17$ & $2.1 \pm 0.3$ \\
\hline & GBW07103 & Biotite granite & $0.014 \pm 0.002$ & $0.033 \pm 0.007$ \\
\hline & GBW07104 & Quartz hornblende andesite & $0.050 \pm 0.008$ & $0.071 \pm 0.009$ \\
\hline & GBW07105 & Olivine basalt & $0.031 \pm 0.005$ & $0.040 \pm 0.008$ \\
\hline & GBW07106 & Quartz sandstone & $0.045 \pm 0.006$ & $0.062 \pm 0.007$ \\
\hline & GBW07107 & Shale & $0.017 \pm 0.003$ & $0.047 \pm 0.009$ \\
\hline & GBW07108 & Argillaceous limestone & $0.026 \pm 0.004$ & $0.043 \pm 0.011$ \\
\hline & GBW07121 & Granite gneiss & $0.019 \pm 0.004$ & $0.03 \pm 0.01$ \\
\hline & GBW07122 & Plagioclase amphibolite & $0.047 \pm 0.005$ & 0.05 \\
\hline & AGV-2 & Andesite & $0.055 \pm 0.004$ & $0.062 \pm 0.001$ \\
\hline Rocks & BCR-2 & Basalt & $0.033 \pm 0.003$ & $0.041 \pm 0.004$ \\
\hline & BHVO-2 & Basalt & $0.047 \pm 0.016$ & $0.050 \pm 0.002$ \\
\hline & BIR-1a & Basalt & $0.013 \pm 0.001$ & 0.036 \\
\hline & DNC-1a & Diabase & $0.028 \pm 0.003$ & 0.027 \\
\hline & DGPM-1 & Gold ore & $0.034 \pm 0.03$ & 0.79 \\
\hline & NOD-A-1 & Manganese nodule & $0.13 \pm 0.015$ & 0.17 \\
\hline & QLO-1a & Quartz latite & $0.018 \pm 0.001$ & 0.062 \\
\hline & SGR-1b & Shale & $0.15 \pm 0.009$ & I \\
\hline & GSP-2 & Granodiorite & $0.084 \pm 0.009$ & l \\
\hline & STM-2 & Syenite & $0.082 \pm 0.011$ & / \\
\hline
\end{tabular}

deviation multiplied by the dilution ratio of the full procedural blank for 11 successive measurements.

Moreover, five geological SRMs (GBW07402, GBW07456, GBW07359, GBW07360, and GBW07105) were assessed for 10 parallel comparative analyses using this method (Table 4). Although Ag is present at ultra-trace levels $\left(<0.20 \mu \mathrm{g} \mathrm{g}^{-1}\right)$ in these geological SRMs, the determined average values are in agreement with the reference values. The relative standard deviations (RSDs) for 10 parallel comparative analyses were $8.9 \%, 7.5 \%, 6.3 \%, 5.6 \%$, and $15.6 \%$ and met the requirements of geochemical sample analysis.

Analysis of Ag in geological reference materials. The proposed method was also employed to determine the $\mathrm{Ag}$ levels in 68geological SRMs, comprising 25 soil samples, 24 stream sediment samples, and 19 rock samples. The results obtained and their certified values are listed in Table S1. The $\mathrm{Ag}$ values determined in18 geological SRMs were lower than the recommended values. Among the 18 SRMs, the recommended $\mathrm{Ag}$ values of 15 samples were less than $0.092 \mu \mathrm{g} \mathrm{g}^{-1}$. If the $\mathrm{Ag}$ content in a sample is too low, stable detection signals cannot be obtained by ICP-MS, and this is the primary reason for the large deviation of the results. It is particularly interesting that all the determined values for the 18 SRMs are lower than the recommended values. We speculate that the water-bath extraction method cannot effectively destroy the lattice of some minerals (gold ore, carbonate rock, etc.), because of which Ag in the lattice cannot be completely released; this results in low values. Moreover, for the samples with a high organic content, such as GBW07107 (the organic matter content is 13-20\%), the adsorption of organic matter will decrease the extraction efficiency of $\mathrm{Ag}$ if organism is not completely removed; this too results in low values. Further studies are required to optimize the 

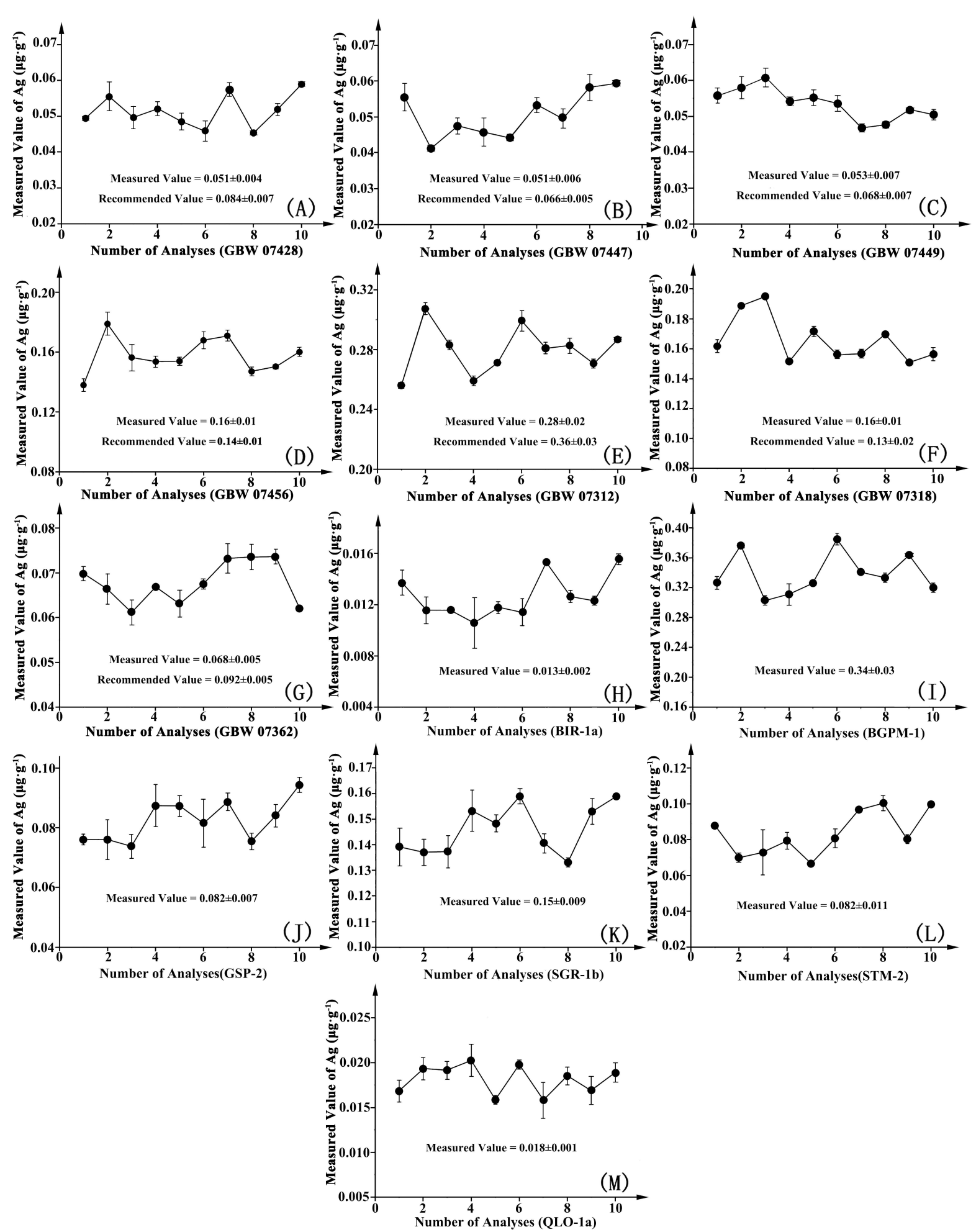

Fig. 5 Reproducibility of Ag values obtained using the proposed method in 13 geological SRMs: GBW07428 (a), GBW07447 (b), GBW07449 (c), GBW07456 (d), GBW07305 (e), GBW07318 (f), GBW07362 (g), BIR-1a (h), BGPM-1 (i), GSP-2 (j), SGR-1b (k), STM-2 (l), and QLO-1a (m). For each SRM, ten separate aliquots of the samples were analyzed over a period of three months. 

21. X. Lin, W. Guo, L. L. Jin, and S. H. Hu, Atom. Spectrosc., 2020, 41, 1-10. https://doi.org/10.46770/AS.2020.01.001

22. Y. Cui, L. L. Jin, H. L. Li, S. H. Hu, and Y. Lian, Atom. Spectrosc., 2020, 41, 87-92. https://doi.org/10.46770/AS.2020.02.006

23. W. X. Wang, X. Dai, W. Guo, L. L. Jin, and S. H. Hu, Atom. Spectrosc., 2020, 41, 74-80.

https://doi.org/10.46770/AS.2020.02.004

24. J. Y. Hu, Z. Liu, and H. Z. Wang, Anal.Chim. Acta, 2002, 451, 329-335. https://doi.org/10.1016/S0003-2670(01)01406-4

25. Z. Xing and L. Qi, Rock Mineral Anal., 2013, 32, 398-401. https://doi.org/10.15898/j.cnki.11-2131/td.2013.03.004

26. Y. B. Zhang, Z. Z. Cheng, and H. Li, Chin. J. Anal. Lab., 2006, 25, 105-108. https://doi.org/10.13595/j.cnki.issn1000-0720.2006.0216

27. X. L. Liu, W. J. Sun, T. Y. Wen, T. F. Wang, W. Z. Sun, Y. X. Li, and J. Guo, Chin. J. Anal. Chem., 2015, 43, 1371-1376. https://doi.org/10.11895/j.issn.0253-3820.150382

28. R. K. Katarina, T. Takayanagi, M. Oshima, and S. Motomizu, Anal. Chim. Acta, 2006, 558, 246-253. https://doi.org/10.1016/j.aca.2005.11.010
29. L. P. Zhou and Z. X. Li, Chin. J. Anal. Lab., 2005, 24, 20-25. https://doi.org/10.13595/j.cnki.issn1000 -0720.2005.0203

30. C. Y. Sun, X. F. Dai, X. L. Dai, B. Chen, and C. J. Zheng, Rock Mineral Anal., 2015, 34, 292-296. https://doi.org/10.15898/j.cnki.11-2131/td.2015.03.005

31. L. Strnad, O. Sebek, M. Fayadov, and J. Vrba, Geostand. Geoanal. Res., 2015, 40, 257-266. https://doi.org/10.1111/j.1751-908X.2015.00368.x

32. Y. Wang, L. A. Baker, and I. D. Brindle. Talanta, 2016, 148, 419-426. https://doi.org/10.1016/j.talanta.2015.11.019

33. J. Xu, Z. C. Hu, Y. S. Liu, S. H. Hu, H. L. Yuan, and S. G, Chin. J. Anal. Chem., 2008, 36, 1493-1498. https://doi.org/10.3321/j.issn:0253-3820.2008.11.008

34. W. Guo, S. H. Hu, J. Y. Zhang, and H. F. Zhang, Sci. Total Environ., 2011, 409, 2981-2986. https://doi.org/10.1016/j.scitotenv.2011.04.011

35. J. L. Xu, X. Xing, R. L. Tang, M. Y. Hu, P. P. Zhang, J. F. Bai, and Q. Zhang, Rock Mineral Anal., 2019, 38, 394-402. https://doi.org/10.15898/j.cnki.11-2131/td.201812070131 